Check for updates

Cite this: J. Mater. Chem. A, 2017, 5, 25545

Received 27th October 2017 Accepted 26th November 2017

DOI: $10.1039 / c 7 t a 09492 b$

rsc.li/materials-a

\section{A general method for boosting the supercapacitor performance of graphitic carbon nitride/graphene hybrids $\uparrow$}

\author{
Runjia Lin, (D) a Zhuangnan Li, (D) a Dina Ibrahim Abou El Amaiem, (D) b \\ Bingjie Zhang, (D) ${ }^{c}$ Dan J. L. Brett, (D) ${ }^{b}$ Guanjie He (D) *a and Ivan P. Parkin (D)*a
}

Graphitic carbon nitride $\left(\mathrm{g}-\mathrm{C}_{3} \mathrm{~N}_{4}\right)$ contains a high $\mathrm{C} / \mathrm{N}$ ratio of $3 / 4$; however, utilizing nitrogen atoms in pseudocapacitive energy storage systems remains a challenge due to the limited number of edge nitrogen atoms and inherent poor electrical conductivity of this semi-conductor material. 3D oxidized g$\mathrm{C}_{3} \mathrm{~N}_{4}$ functionalized graphene composites (GOOCN24), in which reduced graphene oxide providing high electron conductivity acts as a skeleton and hybridises with oxidized g- $\mathrm{C}_{3} \mathrm{~N}_{4}$ segments, were synthesized using a facile two-step solution-based method. Due to the pre-oxidation treatment of $g-C_{3} N_{4}$, which breaks the polymeric nature of $\mathrm{g}-\mathrm{C}_{3} \mathrm{~N}_{4}$ and increases in the proportion of edge nitrogen atoms and the subsequent solubility in water, the GOOCN24 composites used as electrodes for supercapacitors show a specific capacitance as high as $265.6 \mathrm{~F} \mathrm{~g}^{-1}$ in acid electrolyte and $243.8 \mathrm{~F} \mathrm{~g}^{-1}$ in alkaline electrolyte in three-electrode configuration at a current density of $1 \mathrm{~A} \mathrm{~g}^{-1}$. In addition, low internal resistance, excellent rate performance of over $74 \%$ capacitance retention (over a 50 -fold increase in current density), and outstanding cycling stability of over 94\% capacitance retention after 5000 cyclic voltammetry cycles in both alkaline and acid electrolytes was attained. This translated into excellent energy density with appropriate power density when demonstrated in a symmetrical device.

\section{Introduction}

As a class of two-dimensional carbon materials, graphene has been intensively studied in various applications such as photocatalysis and energy storage since its first discovery in $2004 .^{1}$ Graphene is considered a suitable candidate as an electrode material in supercapacitors due to its outstanding chemical and thermal stability, ${ }^{2}$ excellent electrical conductivity, ${ }^{3}$ and ultrahigh theoretical specific surface area (up to $2630 \mathrm{~m}^{2} \mathrm{~g}^{-1}$ ). ${ }^{4}$ For instance, Yu and co-workers have synthesised layer-by-layer structured metal organic framework/graphene oxide hybrid films via a facile route. ${ }^{5}$ Supercapacitors based on this hybrid exhibit high energy and power densities. In addition, a graphene/carbon nanotube $(\mathrm{CNT}) / \mathrm{Co}_{3} \mathrm{O}_{4}$ ternary composite has been synthesised by Zhao et al. ${ }^{6}$ The ternary composite based supercapacitor exhibits a specific capacitance of $77 \mathrm{~F} \mathrm{~g}^{-1}$ at a scan rate of $500 \mathrm{mV} \mathrm{s}^{-1}$. However, like other carbon-based

${ }^{a}$ Christopher Ingold Laboratory, Department of Chemistry, University College London, 20 Gordon Street, London WC1H OAJ, UK. E-mail: guanjie.he.14@ucl.ac.uk; i.p. parkin@ucl.ac.uk

${ }^{b}$ Electrochemical Innovation Lab, Department Chemical Engineering, University College London, London WC1E 7JE, UK

${ }^{c}$ Department of Chemistry, Stony Brook University, Stony Brook, New York, USA

$\uparrow$ Electronic supplementary information (ESI) available. See DOI: $10.1039 / \mathrm{c} 7 \mathrm{ta} 09492 \mathrm{~b}$ supercapacitors, pure graphene-based supercapacitors can only store and release energy electrostatically, which achieves high power density but limits the energy density. Thus, with the purpose of introducing pseudocapacitance to improve the energy density of graphene materials, various functionalization techniques have been developed.

Among current functionalization techniques, modifying graphene by nitrogen functionalization is considered promising. Theoretically speaking, there are four reasons which make nitrogen functionalization a promising approach to improve the properties of graphene-based materials. ${ }^{7}$ Nitrogen is a neighbour of carbon. This implies that only one extra electron will be added to the overall system if one nitrogen atom replaces one carbon atom, which improves the stability of the system as well as the ease of its modification. In addition, nitrogen atoms and carbon atoms have similar radii. Thus, significant mismatch of atomic size can be avoided during functionalization. Furthermore, nitrogen doping can improve overall electrical conductivity and capacitive properties of graphene materials. Moreover, pseudocapacitance is governed by fast surface redox reactions, which are induced by the doped nitrogen functional groups. ${ }^{8}$ Thus, nitrogen functionalization has been widely and successfully used to modify graphene-based electrode materials in supercapacitors. For instance, Sahu and co-workers have synthesised heavily nitrogen-doped graphene by pyrolyzing silk cocoon membrane at $400{ }^{\circ} \mathrm{C} .{ }^{9}$ This material possesses a high specific capacitance of 
$220.5 \mathrm{~F} \mathrm{~g}^{-1}$ at $0.8 \mathrm{~A} \mathrm{~g}^{-1}$ current density based on galvanic charge and discharge test and a relatively small internal resistance of $4.2 \Omega$.

Recently, graphitic carbon nitride $\left(\mathrm{g}-\mathrm{C}_{3} \mathrm{~N}_{4}\right)$ has received substantial research interest in photocatalysis due to its suitable band gap of around $2.9 \mathrm{eV} \cdot{ }^{\mathbf{1 0 - 1 5}}$ Nevertheless, researchers have seldom studied its potential applications as an electrode material in energy storage devices. Since both $\mathrm{g}-\mathrm{C}_{3} \mathrm{~N}_{4}$ and graphene possess similar graphitic microstructures and $\mathrm{g}-\mathrm{C}_{3} \mathrm{~N}_{4}$ contains high-loading of nitrogen functional groups, modifying graphene with $\mathrm{g}-\mathrm{C}_{3} \mathrm{~N}_{4}$ is considered a potentially effective strategy to enhance the performance of graphene-based supercapacitors. Chen et al. have prepared graphene/g- $\mathrm{C}_{3} \mathrm{~N}_{4}$ composites via a hydrothermal reaction. ${ }^{16}$ It is found that the composites show a high specific capacitance of $264 \mathrm{~F} \mathrm{~g}^{-1}$ at a current density of $0.4 \mathrm{~A} \mathrm{~g}^{-1}$ from galvanic charge and discharge test in acid electrolyte medium as well as outstanding cycling stability which retains over $80 \%$ of its initial capacitance after 10000 chargedischarge cycles. In addition, a graphene/porous carbon selfrepairing $\mathrm{g}-\mathrm{C}_{3} \mathrm{~N}_{4}$ composite has been prepared by Ding and coworkers. ${ }^{17}$ The material exhibits a specific capacitance as high as $379.7 \mathrm{~F} \mathrm{~g}^{-1}$ at a current density of $0.25 \mathrm{~A} \mathrm{~g}^{-1}$ from galvanic charge and discharge test and 85\% capacitance retention after 10000 galvanic charge-discharge cycles. However, as a polymeric semiconductor, $\mathrm{g}-\mathrm{C}_{3} \mathrm{~N}_{4}$ without modification suffers from low electrical conductivity and limited functional groups when composited with graphene materials. Its large molecular structure limits the number of edge nitrogen atoms, which are the major contributions for pseudocapacitance. Hence, further research is required to increase the electrochemical performance of the composite materials by increasing the number of edge nitrogen atoms of $\mathrm{g}-\mathrm{C}_{3} \mathrm{~N}_{4}$.

In this work, we developed a facile method to both increase the edge nitrogen content of $\mathrm{g}-\mathrm{C}_{3} \mathrm{~N}_{4}$ and the functional groups for use as strong hinges when combined with graphene materials by pre-oxidizing the $\mathrm{g}-\mathrm{C}_{3} \mathrm{~N}_{4}$. Following the oxidation process, the proportion of edge nitrogen increased significantly by cutting the large $\mathrm{g}-\mathrm{C}_{3} \mathrm{~N}_{4}$ layered structures to smaller segments. Moreover, its electrical conductivity improved substantially when it formed a composite with reduced graphene oxide aerogels. The composite exhibited high specific capacitance, excellent capacitive behaviour and outstanding stability in both alkaline and acid electrolytes.

\section{Experimental section}

All the abbreviations of the materials used are listed in Table S1. $\dagger$ The fabrication process of the composites can be divided into four sections (Fig. S1 $\dagger$ ): (i) preparation of graphene oxide, (ii) preparation of $\mathrm{g}-\mathrm{C}_{3} \mathrm{~N}_{4}$, (iii) oxidation of $\mathrm{g}-\mathrm{C}_{3} \mathrm{~N}_{4}$, and (iv) preparation of composite materials.

\section{Preparation of graphene oxide}

Graphene oxide was manufactured by oxidation of natural graphite powder via improved Hummer's method. ${ }^{18,19}$ Detailed process can be found in ESI. $\dagger$

\section{Preparation of $\mathrm{g}-\mathrm{C}_{3} \mathrm{~N}_{4}$}

Melamine was used as the precursor for the synthesis of $\mathrm{g}^{-} \mathrm{C}_{3} \mathrm{~N}_{4} \cdot{ }^{20}$ More information is available in ESI. $\dagger$

\section{Oxidation of $\mathbf{g}-\mathrm{C}_{3} \mathbf{N}_{4}$}

OCN3, OCN24, and OCN72 were synthesised by oxidizing g$\mathrm{C}_{3} \mathrm{~N}_{4}$ using concentrated nitric acid. $3 \mathrm{~g} g-\mathrm{C}_{3} \mathrm{~N}_{4}$ was mixed with $200 \mathrm{~mL}$ of concentrated $\mathrm{HNO}_{3}$ in a round-bottom flask. Then the system was transferred to a $40{ }^{\circ} \mathrm{C}$ oil bath and heated for $3 \mathrm{~h}, 24 \mathrm{~h}$ or $72 \mathrm{~h}$ with magnetic stirring. The products were then washed to remove residual $\mathrm{HNO}_{3}$ through centrifuge separation. Finally, after lyophilized by freeze-drying, OCN3, OCN24 and OCN72 were synthesized. The preparation of FOCN was achieved by the oxidation of $\mathrm{g}-\mathrm{C}_{3} \mathrm{~N}_{4}$ via improved Hummer's method which is similar to the preparation of graphene oxide.

\section{Preparation of composite materials}

All as-prepared materials were dissolved in deionised water separately to form $2 \mathrm{mg} \mathrm{mL}^{-1}$ solutions. GO was mixed with $\mathrm{CN}$ at different mass ratios of $1 / 1,2 / 1,3 / 1$ and $4 / 1$, respectively. GOCN-1 $\left(m_{\mathrm{GO}} / m_{\mathrm{CN}}=1 / 1\right)$, GOCN-2 $\left(m_{\mathrm{GO}} / m_{\mathrm{CN}}=2 / 1\right)$, GOCN-3 $\left(m_{\mathrm{GO}} / m_{\mathrm{CN}}=3 / 1\right)$, and GOCN-4 $\left(m_{\mathrm{GO}} / m_{\mathrm{CN}}=4 / 1\right)$ were synthesised via hydrothermal reactions to find the optimized ratio. The GOOCN3, GOOCN24, GOOCN72, and GOFOCN samples were prepared via hydrothermal reactions through the same procedure. GO was mixed with OCN3, OCN24, OCN72 or FOCN in a chemical reactor at a mass ratio of $3 / 1$. After stirring at room temperature for $2 \mathrm{~h}$, the reactor was transferred to an oven and heated at $180{ }^{\circ} \mathrm{C}$ for $12 \mathrm{~h}$. The resulting aerogels were washed using water-ethanol solution $(90 \%$ deionised water, $10 \%$ ethanol). Finally, the GOOCN3 $\left(m_{\mathrm{GO}} / m_{\mathrm{OCN} 3}=3 / 1\right)$, GOOCN24 $\left(m_{\mathrm{GO}} / m_{\mathrm{OCN} 24}=3 / 1\right)$, GOOCN72 $\left(m_{\mathrm{GO}} / m_{\mathrm{OCN} 72}=3 / 1\right)$ and GOFOCN $\left(m_{\mathrm{GO}} / m_{\mathrm{FOCN}}=3 / 1\right)$ aerogels were lyophilized.

\section{Fabrication of supercapacitor electrodes}

Nickel foam was used as the current collector of the supercapacitor electrode when tested in alkaline electrolyte. Carbon paper was the current collector choice when measurements were conducted in an acid electrolyte. The fabrication details are in ESI. $\dagger$

\section{Fabrication of symmetrical supercapacitors}

Symmetrical supercapacitors were fabricated using nickel foam, filter paper, and $\mathrm{KOH}$ as a current collector, separator, and electrolyte, respectively. Detailed information about the fabrication process is available in ESI. $\dagger$

\section{Fabrication of asymmetrical supercapacitor}

An asymmetrical supercapacitor was fabricated by constructing the GOOCN24 electrode with an $\mathrm{NiCo}_{2}(\mathrm{OH})_{x} / \mathrm{CNT}$ electrode. Please see $\mathrm{ESI} \dagger$ for detailed information about the fabrication process. 


\section{Electrochemical measurements}

The as-prepared supercapacitor electrodes and symmetrical (or asymmetrical) supercapacitors were tested in a three-electrode and two-electrode system, respectively. The specific capacitance of the electrode in three-electrode system was calculated using the equation: $C_{\text {specific }}=I \Delta t /(m \Delta V)$, where $I, \Delta t, m$, and $\Delta V$ are the discharge current, discharge time, electrode material mass, and potential change within the discharge time, respectively. The specific capacitance of the GOOCN24 electrode in two-electrode system was obtained by the equation: $C_{\mathrm{wt}}=4 I \Delta t$ / ( $\left.m_{\text {total }} \Delta V\right)$, where $C_{\mathrm{wt}}$ and $m_{\text {total }}$ are specific capacitance of GOOCN24 electrode and total active material mass on positive and negative electrodes of the as-assembled device. The gravimetric energy density $\left(E_{\mathrm{G}}\right)$ and gravimetric power density $\left(P_{\mathrm{G}}\right)$ of the active materials on electrodes depicted in Ragone plots were calculated using equations: $E_{\mathrm{G}}=0.5 C_{\mathrm{wt}} \Delta V^{2}$ and $P_{\mathrm{G}}=E_{\mathrm{G}} / \Delta t$. The volumetric energy density $\left(E_{\mathrm{V}}\right)$ and volumetric power density $\left(P_{\mathrm{V}}\right)$ of the as-assembled devices depicted in Ragone plots were calculated using equations: $C_{\mathrm{vol}}=C_{\mathrm{wt}} m_{\text {total }} / V_{\text {cell }}, E_{\mathrm{V}}=C_{\text {cell }} \Delta V^{2} / 8$ and $P_{\mathrm{V}}=E_{\mathrm{V}} / \Delta t$, where $C_{\mathrm{vol}}$ and $V_{\text {cell }}$ are volumetric capacitance of GOOCN24 electrode and volume of the as-assembled supercapacitor, respectively. ${ }^{21}$ The performance of electrodes for combined supercapacitors in series were calculated similarly.

\section{Characterization}

The microstructure and morphology of the samples were characterized using a JSM-6700F scanning electron microscope (SEM) and a JEM-2100F transmission electron microscope (TEM). The chemical states of the samples were explored by $\mathrm{X}$ ray photoelectron spectroscopy analysis (XPS; Thermo Scientific K-alpha photoelectron spectrometer) and Fourier transform infrared spectroscopy analysis (FTIR; Bruker platinumATR Fourier transform infrared spectrometer).

\section{Results and discussion}

The process for the manufacture of GOOCN composites is shown in Fig. 1(a). The oxidation treatment of $\mathrm{g}-\mathrm{C}_{3} \mathrm{~N}_{4}$ by concentrated nitric acid successfully cuts the large layered $\mathrm{g}^{-} \mathrm{C}_{3} \mathrm{~N}_{4}$ molecules to smaller segments. As a result, the proportion of edge nitrogen atoms (pyridinic $\mathrm{N}$, pyrrolic $\mathrm{N}$ ) over all the nitrogen in $\mathrm{g}-\mathrm{C}_{3} \mathrm{~N}_{4}$ is increased theoretically, as illustrated by Fig. 1(b). In addition, oxygen functional groups are also introduced in the polymeric material during the oxidation process, which significantly improves its solubility in water (Fig. S2 $\dagger$ ). ${ }^{22}$ The microstructures were determined by SEM and TEM, Fig. 1(c) and (d). The hydrothermal reduction reaction allows graphene oxide planes and oxidized $\mathrm{g}-\mathrm{C}_{3} \mathrm{~N}_{4}$ segments to form a composite aerogel with $3 \mathrm{D}$ layered microstructures. However, as shown in Fig. 1(e) and (f), CN and OCN24 have different dispersion on graphene oxide layers in GOCN-3 and GOOCN24 composites, respectively (the dispersion differences between GOCN-3 and other GOOCN and GOFOCN samples are displayed in Fig. S3†). Several CN chunks can be observed in Fig. 1(e), which indicates $\mathrm{CN}$ doesn't possess a homogeneous dispersion in GOCN-3 composite. On the contrary, Fig. 1(f) illustrates a more uniform dispersion of OCN24 in GOOCN24 composite when compared to the dispersion of $\mathrm{CN}$ in GOCN-3 composite. It is believed that the dispersion differences between $\mathrm{CN}$ and OCN24 in their corresponding composite materials are the result of their different solubility in water and surface functional groups. OCN24 can form a more homogeneous aqueous solution than $\mathrm{CN}$. Thus, compared with the $\mathrm{CN}$ aqueous solution, OCN24 aqueous solution mixes more evenly with graphene oxide aqueous solution before the hydrothermal reduction reaction, leading to its more uniform dispersion on the graphene oxide layers after the treatment.

The FTIR analysis shown in Fig. 2(a) confirms the presence of various oxygen-containing functional groups in OCN24 sample. The two wide peaks at 3116 and $3305 \mathrm{~cm}^{-1}$ are attributed to the stretching vibrations of hydroxyl $(-\mathrm{OH})$ and amino $(-\mathrm{NH})$ groups, respectively. ${ }^{23}$ Moreover, the presence of $-\mathrm{OH}$ bonds in carboxyl group is identified by the peak at $2761 \mathrm{~cm}^{-1}$. In addition, the sharp peak at $1047 \mathrm{~cm}^{-1}$ is caused by the vibration of $\mathrm{C}-\mathrm{O}$ bonds in the hydroxyl group. ${ }^{24}$ These oxygen-containing functional groups are hydrophilic, resulting in the improved solubility of OCN24 sample in water. On the contrary, except for the broad peak $\sim 3157 \mathrm{~cm}^{-1}$ which corresponds to the stretching vibrations of amino $(-\mathrm{NH})$ groups and surface absorbed water molecules, ${ }^{25}$ no obvious oxygen functional groups related peaks are found in the FTIR spectrum of the CN sample. As a result, CN shows poor solubility in water. Furthermore, in addition to oxygen-containing groups, characteristic $\mathrm{g}-\mathrm{C}_{3} \mathrm{~N}_{4}$ structures can also be identified by FTIR analysis. The sharp intense peak at $\sim 800 \mathrm{~cm}^{-1}$ in the FTIR spectra of both samples is attributed to a "breathing" vibration of the triazine rings in $\mathrm{g}-\mathrm{C}_{3} \mathrm{~N}_{4}{ }^{26}$ As for the peaks in the range between 1200-1650 $\mathrm{cm}^{-1}$ (peaks at 1233, 1389 and $1625 \mathrm{~cm}^{-1}$ for OCN24 and peaks at 1222, 1397, 1541 and $1632 \mathrm{~cm}^{-1}$ for CN), they correspond to the stretching vibrations of aromatic $\mathrm{C}-\mathrm{N}$ bonds in carbon-nitrogen heterocycles. ${ }^{27,28}$

The surface chemical structures and elemental contents of GOCN-3 and GOOCN24 samples were explored by XPS analysis. The XPS survey spectra of GOCN-3 and GOOCN24 are shown in Fig. 2(b). C 1s and C KLL peaks along with O 1s and O KLL peaks of both samples can be clearly seen in the survey spectra. $\mathrm{N} 1 \mathrm{~s}$ and N KLL peaks of GOCN-3 sample were also found in Fig. 2(b), which corresponded to its high nitrogen content of 24.59 at\%. However, only a much lower N 1 s peak and a tiny N KLL signal of GOOCN24 sample was observed in Fig. 2(b). This corresponds to a much lower nitrogen content of GOOCN24 sample (only 2.5 at\%), which is a result of the introduction of oxygencontaining groups to OCN24 sample due to the oxidation treatment and the break of the polymeric structures (detailed carbon, oxygen, and nitrogen contents of the samples can be found in Tables S2 and S3†). Moreover, Fig. 2(c) shows the XPS C 1s spectra of GOCN-3 and GOOCN24 samples which exhibit the chemical relationships of carbon. The peaks centred at $288.2 \mathrm{eV}$ and $288.6 \mathrm{eV}$ belong to $\mathrm{C}-\mathrm{N}=\mathrm{C}$ coordination in $\mathrm{GOCN}-3$ and GOOCN24, respectively. ${ }^{29}$ Peaks corresponding to $\mathrm{C}-\mathrm{C}, \mathrm{C}=\mathrm{C}$, $\mathrm{C}-\mathrm{O}$, and $\mathrm{C}=\mathrm{C}$ coordination in both samples can be found from the $\mathrm{C}$ 1s spectra. ${ }^{30-32}$ Furthermore, the chemical states of the nitrogen in GOCN-3 and GOOCN24 composites are shown in Fig. 2(d). The four peaks in the $\mathrm{N}$ 1s spectrum of GOCN-3 

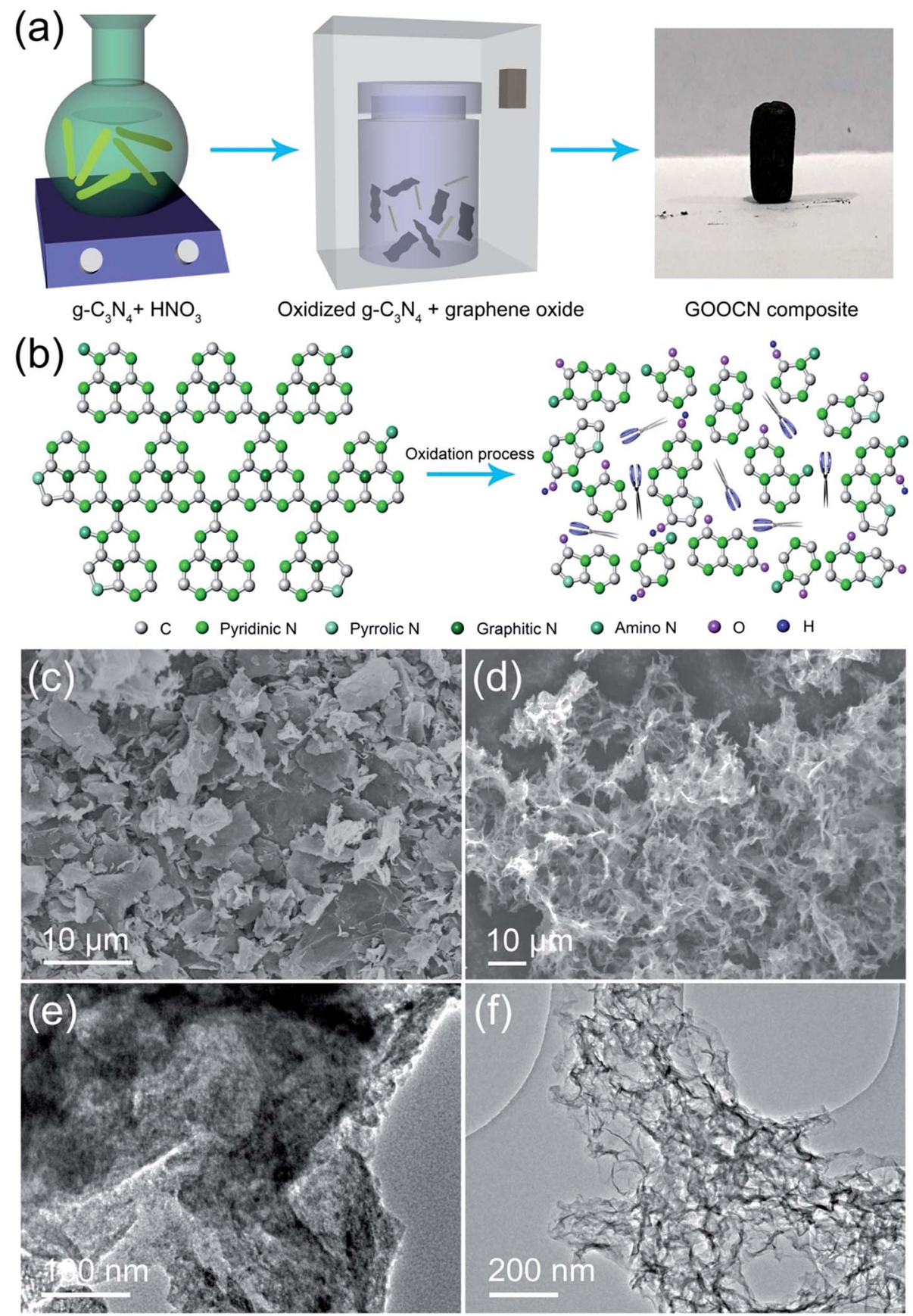

Fig. 1 (a) Synthetic route of GOOCN composites; (b) schematic illustration of predicted g- $\mathrm{C}_{3} \mathrm{~N}_{4}$ before and after oxidation treatment; (c, d) SEM images of (c) GOCN-3 and (d) GOOCN24 at low magnification; (e, f) TEM images of (e) GOCN-3 and (f) GOOCN24 at low magnification.

sample are centred at $398.6 \mathrm{eV}, 399.9 \mathrm{eV}, 401.0 \mathrm{eV}$, and $404.6 \mathrm{eV}$ and attributed to pyridinic $\mathrm{N}$, pyrrolic $\mathrm{N}$, graphitic $\mathrm{N}$ and $\pi-\pi^{*}$ satellite (governed by nitrogen-containing aromatic rings), respectively. ${ }^{33,34}$ Nevertheless, only the peaks of pyridinic $\mathrm{N}$ (398.4 eV), pyrrolic $\mathrm{N}(399.7 \mathrm{eV})$, and $\pi-\pi^{*}$ satellite $(405.7 \mathrm{eV})$ can be observed in the $\mathrm{N} 1 \mathrm{~s}$ spectrum of GOOCN24. This reveals that the graphitic nitrogen in the polymeric material had been successfully converted to edge nitrogen after the oxidation process. Similar situations also occur in other GOOCN and GOFOCN samples (Fig. S4†).
The performances of GOCN-3 and GOOCN24 as electrode materials for supercapacitors were first measured by cyclic voltammetry (CV), galvanic charge-discharge (GCD), and electrochemical impedance spectra (EIS) tests with a three-electrode system in $2 \mathrm{M} \mathrm{KOH}$ electrolyte. Fig. 3(a) displays the CV curves of GOCN-3 and GOOCN24 at a scan rate of $20 \mathrm{mV} \mathrm{s}^{-1}$. It is obvious that the GOOCN24 electrode acquires a much larger area for the $\mathrm{CV}$ curve than GOCN-3 electrode, which reveals its higher specific capacitance, further confirmed by the GCD test in Fig. 3(b). The GOOCN24 electrode possesses a high specific 

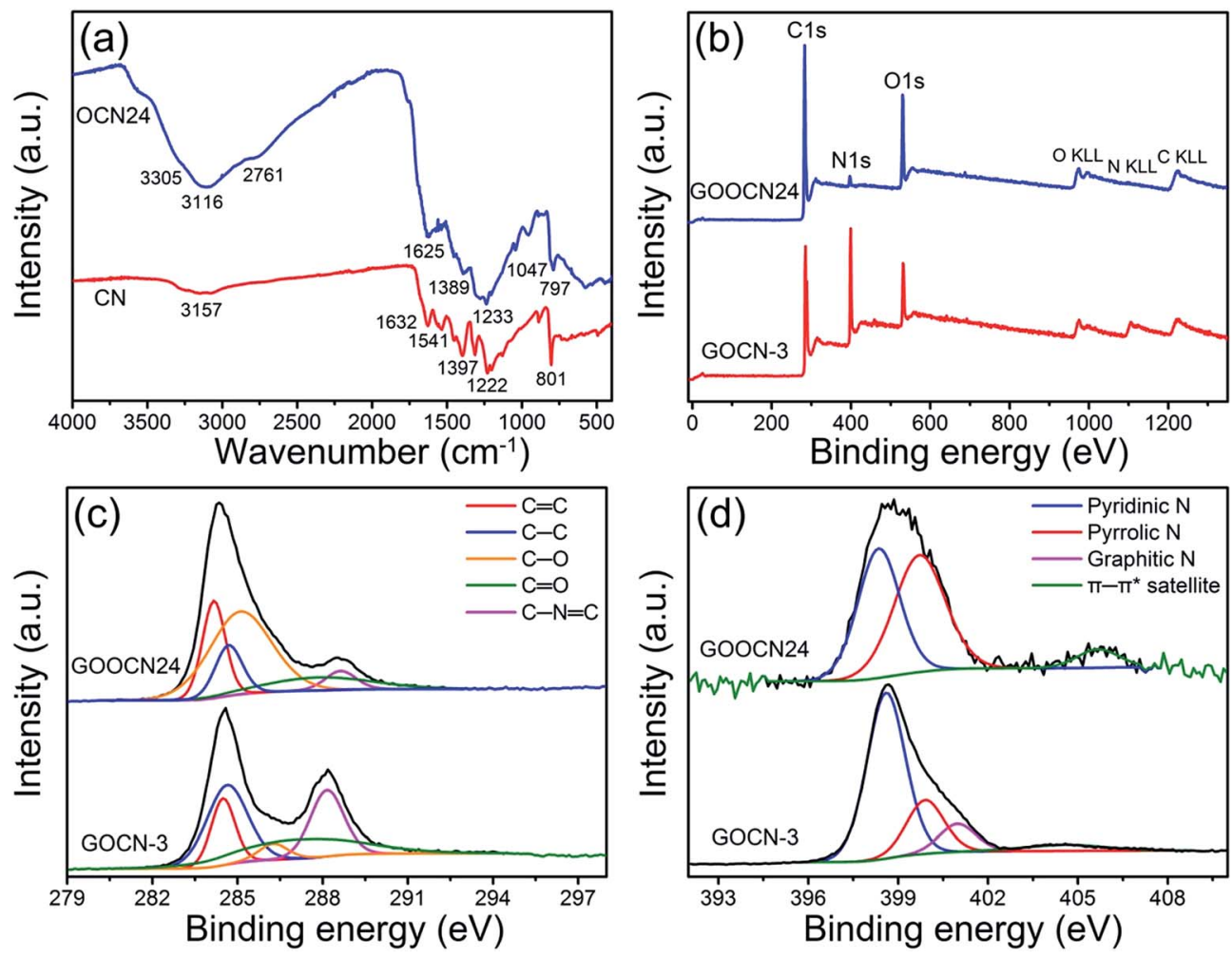

Fig. 2 (a) FTIR spectra of CN and OCN24; (b-d) XPS (b) survey spectra of GOCN-3 and GOOCN24; (c) C 1s and (d) N 1s spectra of GOCN-3 and GOOCN24, respectively.

capacitance of $243.8 \mathrm{~F} \mathrm{~g}^{-1}$ at a current density of $1 \mathrm{~A} \mathrm{~g}^{-1}$, much higher than that of the GOCN-3 electrode $\left(167.9 \mathrm{~F} \mathrm{~g}^{-1}\right)$ at the same current density. No obvious potential drop appears, implying smaller internal resistance of this sample. It is noteworthy that during supercapacitor charge-discharge process, oxygen functional groups induced redox reactions such as $>\mathrm{C}-$ $\mathrm{OH} \leftrightarrow \mathrm{C}-\mathrm{O}+\mathrm{H}^{+}+\mathrm{e}^{-},-\mathrm{COOH} \leftrightarrow-\mathrm{COO}+\mathrm{H}^{+}+\mathrm{e}^{-}$, and $>\mathrm{C}-\mathrm{O}+$ $\mathrm{e}^{-} \leftrightarrow \mathrm{C}^{-} \mathrm{O}^{-}$may occur, resulting in the improved specific capacitance of the supercapacitor..$^{35}$ Hence, it is believed higher content of oxygen functional groups in GOOCN24 sample is one of reasons leads to its higher specific capacitance. Moreover, kinetic analysis was also conducted to investigate the capacitance contribution from surface capacitive effects and diffusion controlled processes at the GOOCN24 electrode. ${ }^{36}$ As shown in Fig. 3(c), the contribution of surface capacitive effects and diffusion controlled processes are $86.6 \%$ and $13.4 \%$, respectively. Therefore, the surface capacitive effects are believed to dominate the capacitance of the GOOCN24 sample, whereby similar results can be detected from the GOCN-3 sample (Fig. S5(a), $\dagger 65.6 \%$ of total capacitance is a result of surface capacitive effects in GOCN-3 sample). The higher ratio of the surface-controlled process may provide better rate performance due to faster electrochemical reactions. To further investigate the rate performance of GOCN-3 and GOOCN24 electrodes, GCD tests were also conducted at current densities of $2,5,10$, 20 , and $50 \mathrm{~A} \mathrm{~g}^{-1}$, as shown in Fig. 3(d) and S6. $\dagger$ It can be found that GOOCN24 still retains a higher specific capacitance of $136.4 \mathrm{~F} \mathrm{~g}^{-1}$ at $50 \mathrm{~A} \mathrm{~g}^{-1}$ current density $(59 \%$ of its value at
$1 \mathrm{~A} \mathrm{~g}^{-1}$ ) compared to only $28.3 \mathrm{~F} \mathrm{~g}^{-1}\left(17 \%\right.$ of its value at $1 \mathrm{~A} \mathrm{~g}^{-1}$ ) for the GOCN-3 sample. The results of rate performance are in accordance with the kinetic analysis of $\mathrm{CV}$ curves.

The excellent electrochemical performance of the GOOCN24 sample in alkaline electrolyte can be attributed to its improved electronic conductivity and capacitive behaviour, confirmed by the EIS measurements. As displayed in Fig. 3(e), the Nyquist plot of GOOCN24 electrode features a nearly vertical line from the low frequency range, indicating its ideal capacitive performance. The insert of Fig. 3(e) shows that the Nyquist plot of GOOCN24 electrode possesses a smaller Warburg region and a small depressed semicircle. This implies it has a lower charge transfer resistance and better electrolyte ion diffusion when compared to the GOCN-3 electrode. With the purpose of further comparing the interfacial electrochemical behaviours of GOCN3 and GOOCN24 electrodes, an equivalent circuit (Fig. S7†) was introduced to fit the Nyquist plots (Table S4 $\dagger$ ). ${ }^{37}$ The internal resistance $\left(R_{\mathrm{s}}=0.95 \Omega\right)$ and charge transfer resistance $\left(R_{\mathrm{ct}}=\right.$ $0.06 \Omega$ ) of the GOOCN24 electrode are smaller than that of the GOCN-3 electrode $\left(R_{\mathrm{S}}=1.04 \Omega, R_{\mathrm{ct}}=1.05 \Omega\right)$. The low resistance values indicate the higher electron conductivity and ion migration speed of the GOOCN24 electrode over the GOCN-3 electrode. It is believed that the oxidation treatment of g- $\mathrm{C}_{3} \mathrm{~N}_{4}$ results in the higher electron conductivity of GOOCN24 material by breaking the polymeric structures and inducing higher contents of edge $\mathrm{N}$ and $\mathrm{O}$ doping of the composites. In addition, it is recognizable that the more homogeneous dispersion of OCN24 on graphene oxide layers leads to better ion diffusion 

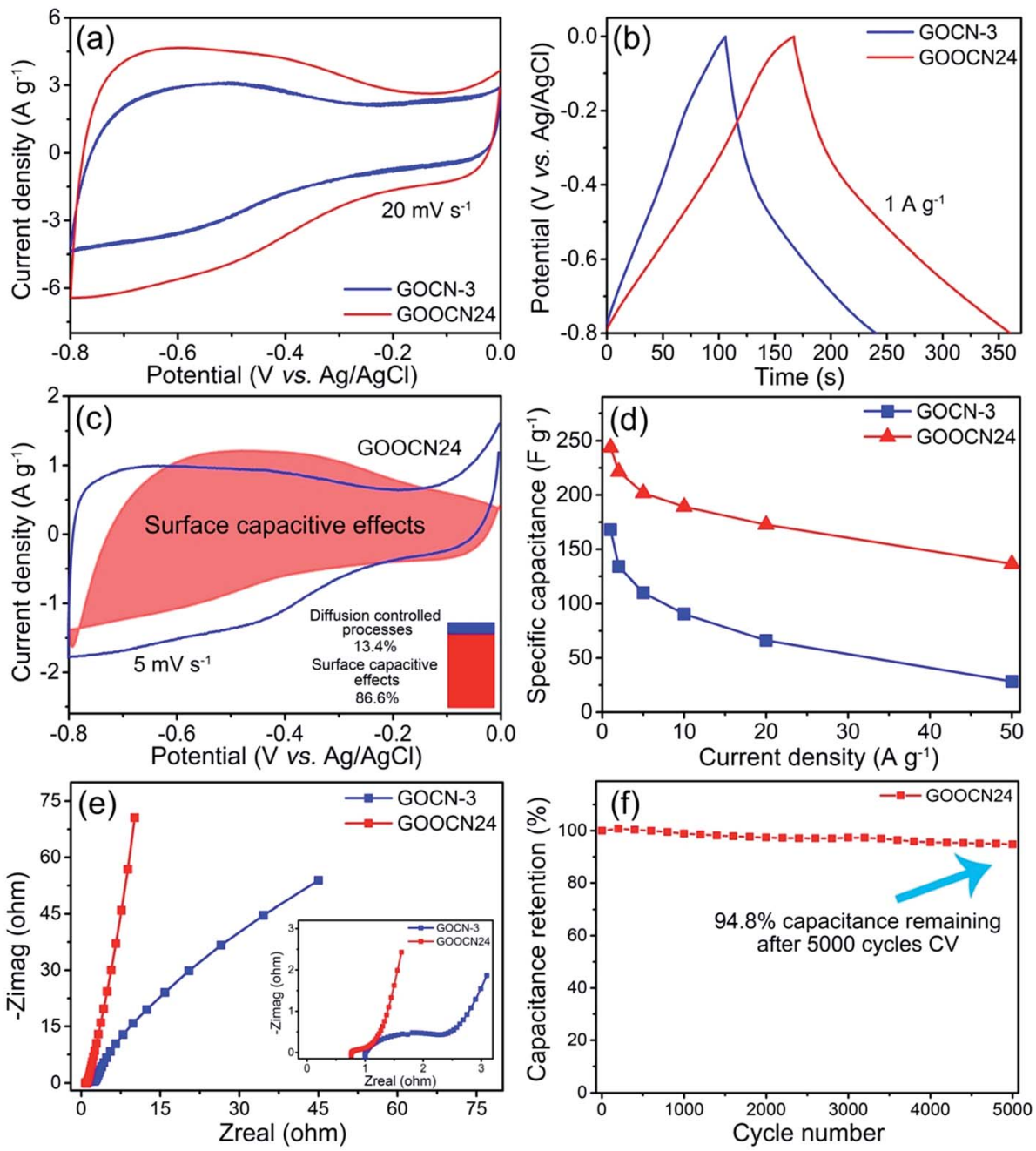

Fig. 3 Electrochemical tests results of GOCN-3 and GOOCN24 based electrodes in alkaline electrolyte (a) CV plots of GOCN-3 and GOOCN24 electrodes measured at a scan rate of $20 \mathrm{mV} \mathrm{s}^{-1}$; (b) GCD test results of GOCN-3 and GOOCN24 electrodes at a current density of $1 \mathrm{~A} \mathrm{~g}^{-1}$; (c) kinetic analysis of GOOCN24 electrode from CV curves; (d) rate performance of GOCN-3 and GOOCN24 electrodes; (e) Nyquist plots of GOCN3 and GOOCN24 electrodes; (f) cycling stability test of GOOCN24 electrode at a scan rate of $100 \mathrm{mV} \mathrm{s}^{-1}$.

ability of GOOCN24 sample. The higher solubility in water of OCN24 avoids the aggregation of the polymeric material on the graphene oxide layers as more channels are available for ion transportation within the GOOCN24 sample. As a result, ions can move more freely without being hindered by large polymeric chunks.

Cycling stability test was also performed to evaluate the potentials of these materials for practical applications. Fig. 3(f) displays the temporal evolution of GOOCN24's specific capacitance over consecutive CV tests. It can be found that GOOCN24 retains $94.8 \%$ of its initial capacitance after $5000 \mathrm{CV}$ cycles at a high scan rate of $100 \mathrm{mV} \mathrm{s}^{-1}$, indicating an excellent longterm stability of the GOOCN24 electrode.

In order to further explore the practical application potential of GOOCN24 composite, a symmetrical supercapacitor using GOOCN24 and $2 \mathrm{M} \mathrm{KOH}$ as the electrode material and electrolyte, respectively were assembled and measured in a twoelectrode configuration. As depicted in Fig. 4(a), the CV curves of GOOCN24 electrode exhibit nearly rectangular shapes, revealing its ideal electrical double layer behaviour. Moreover, it is worth mentioning that the quasi-rectangular shape of the CV curve remains nearly unchanged when the scan rate was increased from $1 \mathrm{mV} \mathrm{s}^{-1}$ to $20 \mathrm{mV} \mathrm{s}{ }^{-1}$, indicating outstanding rate performance. Furthermore, GCD measurements at six different current densities ranging from $0.1 \mathrm{~A} \mathrm{~g}^{-1}$ to $5.0 \mathrm{~A} \mathrm{~g}^{-1}$ and corresponding calculated specific capacitance are displayed in Fig. 4(b) and (c), respectively. The specific capacitance of GOOCN24 electrode in a symmetrical device at a $0.1 \mathrm{~A} \mathrm{~g}^{-1}$ current density can reach as high as $170.7 \mathrm{~F} \mathrm{~g}^{-1}$. As shown in Fig. 4(c), the electrode possesses a specific capacitance of $87.2 \mathrm{~F} \mathrm{~g}^{-1}$ when the current density was increases to $5 \mathrm{~A} \mathrm{~g}^{-1}$. These decent electrochemical performance value show that GOOCN24 has promising industrialization potential as electrodes for a supercapacitor.

EIS test was conducted to further evaluate its electronic conductivity and capacitive behaviour. From the Nyquist plot represented in Fig. 4(d), the insertion point on the real axis has a small value which indicates a small internal resistance value 

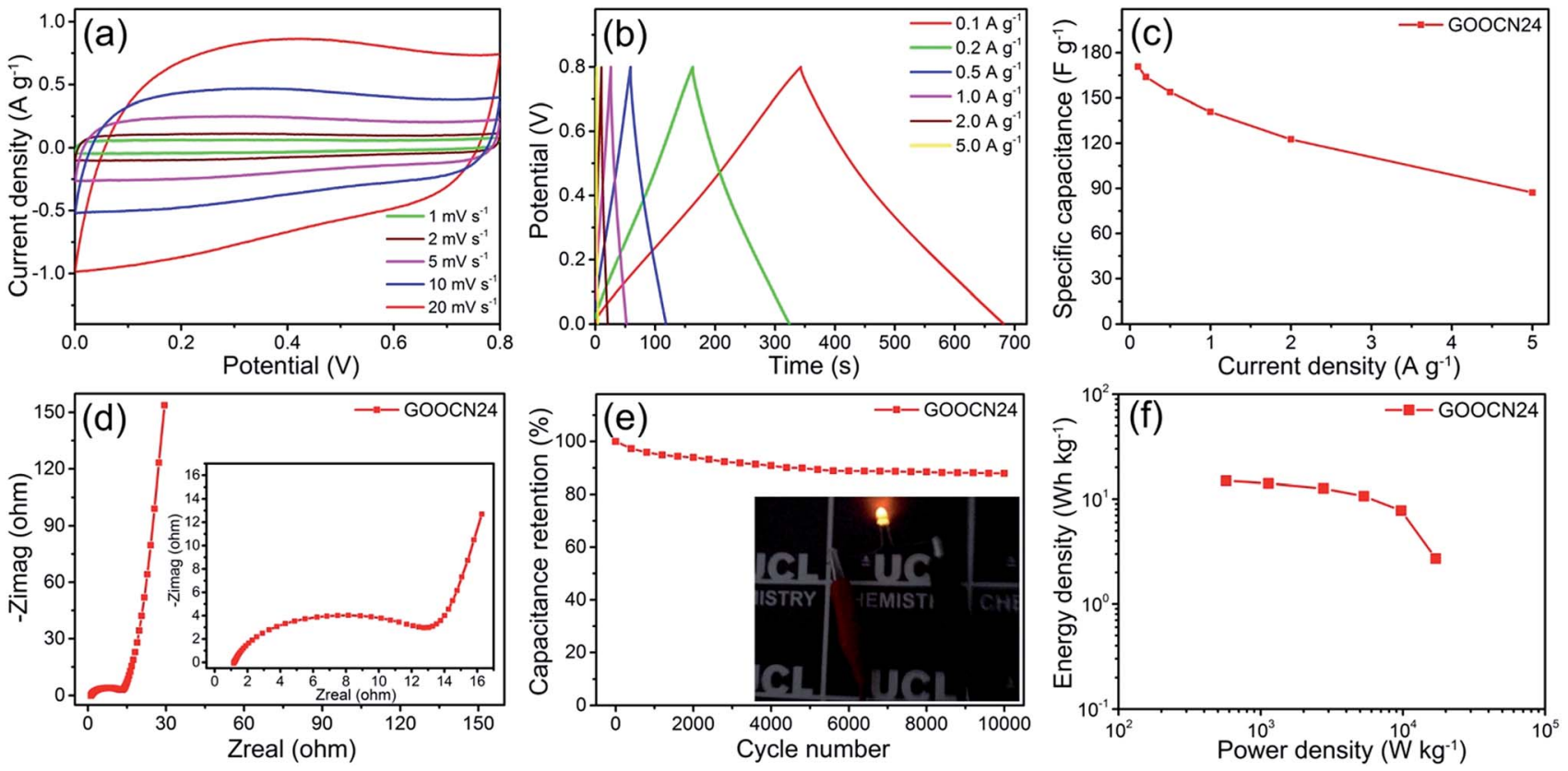

Fig. 4 Electrochemical tests results of GOOCN24 based symmetrical supercapacitor using $2 \mathrm{M} \mathrm{KOH}$ as the electrolyte (a) CV plots of GOOCN24 supercapacitor at a scan rate range between 1 to $20 \mathrm{mV} \mathrm{s}^{-1}$; (b) GCD test results of GOOCN24 supercapacitor at a current density range between 0.1 to $5 \mathrm{~A} \mathrm{~g}^{-1}$; (c) rate performance of GOOCN24 supercapacitor; (d) Nyquist plots of GOOCN24 supercapacitor; (e) cycling stability test of GOOCN24 supercapacitor at a scan rate of $100 \mathrm{mV} \mathrm{s}^{-1}$; (f) Ragone plot of GOOCN24 supercapacitor.

of the supercapacitor. In addition, the Nyquist plot also possesses a small semicircle in the frequency region, revealing a low charge transfer resistance value of the supercapacitor (Table S5†). In addition to good interfacial electrochemical performance, GOOCN24 supercapacitor has decent cycling stability. According to the results shown in Fig. 4(e), only 12.1\% capacitance loss was observed after $10000 \mathrm{CV}$ cycles compared to its initial value. To further investigate the practical application potential of these materials, a device consisting of two symmetrical supercapacitors (connected in series) was also fabricated and evaluated. The detailed electrochemical performance of two symmetrical supercapacitors in series were presented in Fig. S8. $\dagger$ As shown in the insert figure in Fig. 4(e), the device successfully powered a light-emitting diode (LED) to its standard working condition. Hence, we can conclude GOOCN24 has huge industrialization potential as supercapacitor electrode.

Fig. 4(f) shows the Ragone plot representing gravimetric energy density vs. gravimetric power density of GOOCN24 electrode in the as-assembled supercapacitor. The gravimetric energy density is $14.93 \mathrm{~W} \mathrm{~h} \mathrm{~kg}^{-1}$ and the gravimetric power density is $571.36 \mathrm{~W} \mathrm{~kg}^{-1}$ at a current density of $0.1 \mathrm{~A} \mathrm{~g}^{-1}$. When the gravimetric power density increases to $17028.26 \mathrm{~W} \mathrm{~kg}^{-1}$, the supercapacitor retains a gravimetric energy density of $2.71 \mathrm{~W} \mathrm{~h} \mathrm{~kg}^{-1}$. In addition, a Ragone plot representing volumetric energy density $v s$. volumetric power density of the asassembled symmetrical device are shown in Fig. S9. $\dagger$ The volumetric energy density and the volumetric power density of the device is $0.022 \mathrm{~W} \mathrm{~h} \mathrm{~L}^{-1}$ and $0.85 \mathrm{~W} \mathrm{~L}^{-1}$, respectively at a current density of $0.1 \mathrm{~A} \mathrm{~g}^{-1}$. When the volumetric power density boosts to $25.48 \mathrm{~W} \mathrm{~kg}^{-1}$, the device still possesses a volumetric energy density of $0.004 \mathrm{~W} \mathrm{~h} \mathrm{~kg}^{-1}$.

To illustrate the influence of the supercapacitor performance from the concentration of the electrolyte, a symmetrical supercapacitor using GOOCN24 in $6 \mathrm{M} \mathrm{KOH}$ was also fabricated. The electrochemical behaviour demonstrated in Fig. S10 $\uparrow$ shows more rectangular CV curves and better cycling stability (94.4\% capacitance retention after $24000 \mathrm{CV}$ cycles at a scan rate of $100 \mathrm{mV} \mathrm{s}^{-1}$ ) compared to the one with $2 \mathrm{M} \mathrm{KOH}$ electrolyte. This result demonstrates that as-synthesized materials can work more steadily in high concentration electrolyte due to faster ion transfer.

In order to further investigate the applicability of GOOCN24 material as supercapacitor electrode, the GOOCN24 electrode was constructed with an $\mathrm{NiCo}_{2}(\mathrm{OH})_{x} / \mathrm{CNT}$ electrode to constitute an asymmetrical supercapacitor, which was evaluated by CV and GCD tests (Fig. S11†). It is found that the as-fabricated asymmetrical device possesses an operating potential window of $0-1.4 \mathrm{~V}$.

With the purpose of exploring the improved electrochemical performance in other aqueous electrolytes, GOOCN24 and GOCN-3 were also compared and tested in $1 \mathrm{M} \mathrm{H}_{2} \mathrm{SO}_{4}$ aqueous solution by CV, GCD, and EIS tests in a three-electrode system. Before the tests in acid electrolyte, the GOCN-3 and GOOCN24 electrodes were fully activated by a cycling $\mathrm{CV}$ test. The $\mathrm{CV}$ plots of GOCN-3 and GOOCN24 samples at $20 \mathrm{mV} \mathrm{s}^{-1}$ scan rate are illustrated in Fig. 5(a). It is obvious that the GOOCN24 electrode has a larger CV curve area than that of GOCN-3 electrode, indicating it has better electrochemical performance in acid electrolyte. It can be easily observed that the CV plots of both 

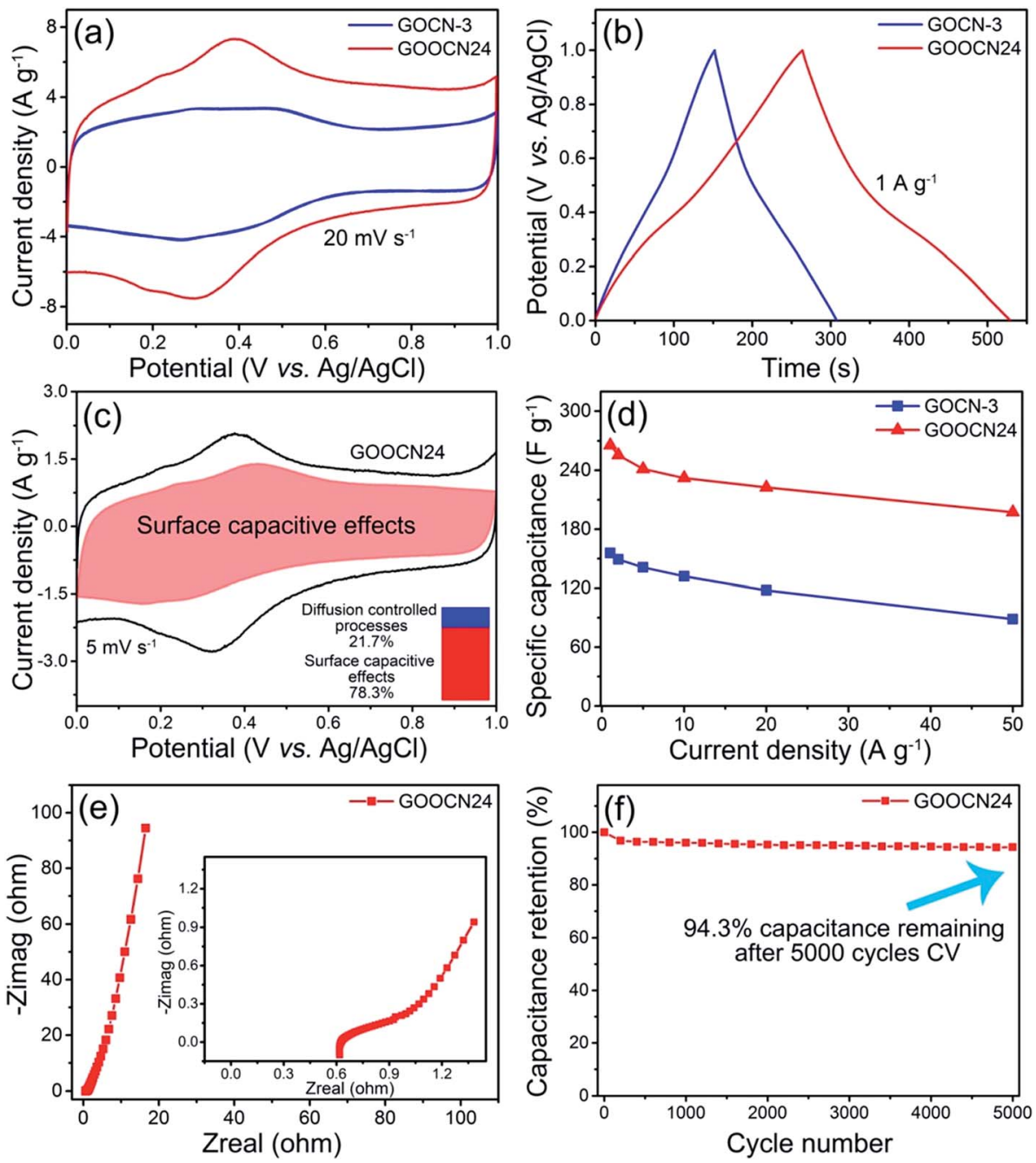

Fig. 5 Electrochemical tests results of GOCN-3 and GOOCN24 based electrodes in acid electrolyte (a) CV plots of GOCN-3 and GOOCN24 electrodes measured at a scan rate of $20 \mathrm{mV} \mathrm{s}^{-1}$; (b) GCD test results of GOCN-3 and GOOCN24 electrodes at a current density of $1 \mathrm{~A} \mathrm{~g}^{-1}$; (c) kinetic analysis of GOOCN24 electrode from CV curves; (d) rate performance of GOCN-3 and GOOCN24 electrodes; (e) Nyquist plots of GOCN3 and GOOCN24 electrodes; (f) cycling stability test of GOOCN24 electrode at a scan rate of $100 \mathrm{mV} \mathrm{s}^{-1}$.

GOCN-3 and GOOCN24 electrodes show redox reaction peaks, revealing redox reactions occur probably between protons in the electrolytes and pyrrolic or pyridinic nitrogen atoms in nitrogen functional groups at the surface of composites during the charge and discharge processes $\left(>\mathrm{N}+\mathrm{H}^{+}+\mathrm{e}^{-} \leftrightarrow{ }_{>} \mathrm{NH}\right) \cdot{ }^{38}$ It is worth mentioning that the redox peaks of GOOCN24 sample are much more distinct than that of the GOCN-3 sample. This indicates that the GOOCN24 composite is more capable of producing pseudocapacitance than the GOCN-3 composite, which confirms the success of converting graphitic nitrogen in g- $\mathrm{C}_{3} \mathrm{~N}_{4}$ to other nitrogen atoms contributing to pseudocapacitance via oxidation treatment. Furthermore, the result of GCD test conducted at $1 \mathrm{~A} \mathrm{~g}^{-1}$ current density is displayed in Fig. 5(b). The specific capacitance of the GOOCN24 electrode can reach $265.6 \mathrm{~F} \mathrm{~g}^{-1}$, which is approximately $60 \%$ larger than the specific capacitance of GOCN-3 electrode. In addition, according to kinetic analysis in Fig. 5(c), although $78.3 \%$ of the GOOCN24 electrode's capacitance comes from surface capacitive effects, the proportion of capacitance produced by diffusion controlled process is $21.7 \%$ in acid electrolyte which is higher than the value obtained in alkaline electrolyte. This announces that GOOCN24 has a better ion diffusion behaviour in acid electrolyte due to the smaller hydrodynamic radius of $\mathrm{H}^{+}$ ions compared to $\mathrm{OH}^{-}$ions, suggesting one of the reasons for higher specific capacitance in acid electrolytes compared to alkaline. The rate performances of both electrodes in acid electrolyte are illustrated in Fig. 5(d). The GOOCN24 electrode possesses a high specific capacitance of $197.2 \mathrm{~F} \mathrm{~g}^{-1}$ at $50 \mathrm{~A} \mathrm{~g}^{-1}$ current density (74\% of its value at $1 \mathrm{~A} \mathrm{~g}^{-1}$ current density), which is far better than that of GOCN-3 electrode $\left(88.5 \mathrm{~F} \mathrm{~g}^{-1}\right.$ at $50 \mathrm{~A} \mathrm{~g}^{-1}$ current density), indicating the outstanding rate performance of GOOCN24 electrode. Moreover, it is worth mentioning that both GOCN-3 and GOOCN24 possess better rate performance in acid electrolyte compared to alkaline electrolyte. This also can be further explained by the smaller hydrodynamic radius of $\mathrm{H}^{+}$ions than $\mathrm{OH}^{-}$ions and intrinsic 
nature of kinetic mechanisms of surface redox reactions within nitrogen/oxygen atoms in carbon matrix and these ions. ${ }^{39-41}$

An EIS test was performed to further explain the tremendous electrochemical performance of GOOCN24 in acid electrolyte. The Nyquist plot displayed in Fig. 5(e) shows that GOOCN24 has a very small internal resistance and no obvious semicircle indicating a small charge transfer resistance. According to the data obtained by fitting the Nyquist plot using an equivalent circuit (Fig. S7 $\dagger$ ), the internal resistance and charge transfer resistance of GOOCN24 are $0.78 \Omega$ and $0.04 \Omega$, respectively. It is obvious that the charge transfer resistance of GOOCN24 in acid electrolyte is much smaller than that in alkaline solution. It is believed that smaller charge transfer resistance value is one of the main reasons that lead to a far more outstanding electrochemical performance of GOOCN24 composite in acid electrolyte when compared to its performance in alkaline electrolyte.

The stability of GOOCN24 electrode in acid electrolyte was examined after $5000 \mathrm{CV}$ cycles conducted at a scan rate of $100 \mathrm{mV} \mathrm{s}^{-1}$. It is shown in Fig. 5(f) that the GOOCN24 electrode still retains over $94 \%$ of its initial capacitance after the stability test, further confirming the excellent stability of GOOCN24 composite in acid electrolyte.

\section{Conclusion}

In summary, the designed 3D GOOCN24 composite exhibits significant performance improvement in supercapacitance when compared to GOCN-3 composite due to the pre-oxidation treatment of $\mathrm{g}-\mathrm{C}_{3} \mathrm{~N}_{4}$ which breaks up the polymeric structures of the material, improves the electronic conductivity, the solubility in water and enlarges the active sites for surface redox reaction in aqueous electrolytes in supercapacitor applications. The excellent specific capacitance as high as $265.6 \mathrm{~F} \mathrm{~g}^{-1}$ and $243.8 \mathrm{~F} \mathrm{~g}^{-1}$, respectively in acid and alkaline electrolyte was measured in three-electrode configuration. These capacitance values are nearly $60 \%$ and $45 \%$ higher than the corresponding specific capacitance of GOCN-3 composite made by the unpretreated process. The material possesses excellent cycling stability of over $94 \%$ capacitance retention after $5000 \mathrm{CV}$ cycles in both alkaline and acid electrolyte. Moreover, in practical devices, the composite can achieve a remarkably high specific capacitance of $170.7 \mathrm{~F} \mathrm{~g}^{-1}$ as well as high energy density of $7.47 \mathrm{~W} \mathrm{~h} \mathrm{~kg}{ }^{-1}$. The pre-oxidation treatment of $\mathrm{g}-\mathrm{C}_{3} \mathrm{~N}_{4}$ can be a general method for modification of these materials as well as nitrogen functionalization of not only carbon materials, but also some metal oxides/ sulphides in the areas of energy storage and catalysis.

\section{Conflicts of interest}

There are no conflicts to declare.

\section{Acknowledgements}

This work was financially supported by EPSRC Centre for Doctoral Training in Molecular Modeling and Materials Science (EP/L015862/1).

\section{References}

1 K. S. Novoselov, A. K. Geim, S. V. Morozov, D. Jiang, Y. Zhang, S. V. Dubonos, I. V. Grigorieva and A. A. Firsov, Science, 2004, 306, 666-669.

2 F. Bonaccorso, L. Colombo, G. Yu, M. Stoller, V. Tozzini, A. C. Ferrari, R. S. Ruoff and V. Pellegrini, Science, 2015, 347, 1246501.

3 Y. Shao, M. El Kady, L. Wang, Q. Zhang, Y. Li, H. Wang, M. Mousavi and R. Kaner, Chem. Soc. Rev., 2015, 44, 36393665.

4 A. Peigney, C. Laurent, E. Flahaut, R. R. Bacsa and A. Rousset, Carbon, 2001, 39, 507-514.

5 D. Yu, L. Ge, X. Wei, B. Wu, J. Ran, H. Wang and T. Xu, J. Mater. Chem. A, 2017, 5, 16865-16872.

6 M. Q. Zhao, Q. Zhang, J. Q. Huang, G. L. Tian, T. C. Chen, W. Z. Qian and F. Wei, Carbon, 2013, 54, 403-411.

7 K. N. Wood, R. O'Hayre and S. Pylypenko, Energy Environ. Sci., 2014, 7, 1212-1249.

8 H. Jin, X. Wang, Z. Gu, Q. Fan and B. Luo, J. Power Sources, 2015, 273, 1156-1162.

9 V. Sahu, S. Grover, B. Tulachan, M. Sharma, G. Srivastava, M. Roy, M. Saxena, N. Sethy, K. Bhargava, D. Philip, H. Kim, G. Singh, S. Singh, M. Das and R. Sharma, Electrochim. Acta, 2015, 160, 244-253.

10 R. Godin, Y. Wang, M. A. Zwijnenburg, J. Tang and J. R. Durrant, J. Am. Chem. Soc., 2017, 139, 5216-5224.

11 S. A. Shevlin and Z. X. Guo, Chem. Mater., 2016, 28, 72507256.

12 J. A. Moniz, S. A. Shevlin, D. J. Martin, Z. X. Guo and J. Tang, Energy Environ. Sci., 2015, 8, 731-759.

13 Y. Wang, L. Li, Y. Wei, J. Xue, H. Chen, L. Ding, J. Caro and H. Wang, Angew. Chem., Int. Ed., 2017, 56, 8974.

14 S. Cao, Q. Huang, B. Zhu and J. Yu, J. Power Sources, 2017, 351, 151-159.

15 X. Zhang, X. Xie, H. Wang, J. Zhang, B. Pan and Y. Xie, J. Am. Chem. Soc., 2013, 135, 18-21.

16 Q. Chen, Y. Zhao, X. Huang, N. Chen and L. Qu, J. Mater. Chem. A, 2015, 3, 6761-6766.

17 Y. Ding, Y. Tang, L. Yang, Y. Zeng, J. Yuan, T. Liu, S. Zhang, C. Liu and S. Luo, J. Mater. Chem. A, 2016, 4, 14307-14315.

18 W. Li, R. Xu, M. Ling and G. He, Opt. Mater., 2017, 72, 529532.

19 G. He, M. Qiao, W. Li, Y. Lu, T. Zhao, R. Zou, B. Li, J. Darr, J. Hu, M. M. Titirici and I. Parkin, Adv. Sci., 2017, 4, 1600214. 20 J. Liu, Y. Liu, N. Liu, Y. Han, X. Zhang, H. Huang, Y. Lifshitz, J. Zhong and Z. Kang, Science, 2015, 347, 970-974.

21 G. He, J. Li, W. Li, B. Li, N. Noor, K. Xu, J. Hu and I. Parkin, J. Mater. Chem. A, 2015, 3, 14272-14278.

22 S. D. F. Brandão, D. Andrada, A. F. Mesquita, A. P. Santos, H. F. Gorgulho, R. Paniago, M. A. Pimenta, C. Fantini and C. A. Furtado, J. Phys.: Condens. Matter, 2010, 22, 334222.

23 A. Kharlamov, M. Bondarenko, G. Kharlamova and V. Fomenko, J. Solid State Chem., 2016, 241, 115-120.

24 Y. Zheng, L. Lin, B. Wang and X. Wang, Angew. Chem., Int. Ed., 2015, 54, 12868-12884. 
25 B. Tahir and M. Tahir, Appl. Surf. Sci., 2017, 419, 875-885. 26 G. Xin and Y. Meng, J. Chem., 2013, 2013, 1-5.

27 K. Katsumata, R. Motoyoshi, N. Matsushita and K. Okada, J. Hazard. Mater., 2013, 260, 475-482.

28 Q. Lv, C. Cao, C. Li, J. Zhang, H. Zhu, X. Kong and X. Duan, J. Mater. Chem., 2003, 13, 1241-1243.

29 Z. H. Sheng, L. Shao, J. J. Chen, W. J. Bao, F. B. Wang and X. H. Xia, ACS Nano, 2011, 5, 4350-4358.

30 A. P. Terzyk, M. Wiśniewski, P. Gauden, G. Rychlicki and S. Furmaniak, J. Colloid Interface Sci., 2008, 320, 40-51.

31 Y. Deng, K. Liu, H. Cao, M. Luo and H. Yan, J. Iran. Chem. Soc., 2015, 12, 807-814.

32 K. Dai, L. Lu, Q. Liu, G. Zhu, X. Wei, J. Bai, L. Xuan and H. Wang, Dalton Trans., 2014, 43, 6295-6299.

33 Y. Zheng, Z. Zhang and C. Li, J. Mol. Catal. A: Chem., 2016, 423, 463-471.

34 M. Roberts, P. Johns, J. Owen, D. Brandell, K. Edstrom, G. El Enany, C. Guery, D. Golodnitsky, M. Lacey, C. Lecoeur,
H. Mazor, E. Peled, E. Perre, M. Shaijumon, P. Simon and P. L. Taberna, J. Mater. Chem., 2011, 21, 9876.

35 Z. Li, S. Gadipelli, Y. Yang and Z. X. Guo, Small, 2017, 13, 1702474.

36 F. Zhang, T. Liu, M. Li, M. Yu, Y. Luo, Y. Tong and Y. Li, Nano Lett., 2017, 17, 3097-3104.

37 Y. Shao, M. El Kady, C. W. Lin, G. Zhu, K. Marsh, J. Hwang, Q. Zhang, Y. Li, H. Wang and R. Kaner, Adv. Mater., 2016, 28, 6719-6726.

38 E. J. Ra, M. H. Tran, S. Yang, T. H. Kim, C. S. Yang, Y. J. Chung, Y. K. Lee, I. J. Kim and H. K. Jeong, Curr. Appl. Phys., 2014, 14, 82.

39 Z. Chen, R. Cao, Y. Ge, Y. Tu, Y. Xia and X. Yang, J. Power Sources, 2017, 363, 356-364.

40 L. Xie, G. Sun, F. Su, X. Guo, Q. Kong, X. Li, X. Huang, L. Wan, W. Song, K. Li, C. Lv and C. M. Chen, J. Mater. Chem. A, 2016, 4, 1637-1646.

41 H. T. Fang, M. Liu, D. W. Wang, X. H. Ren and X. Sun, Nano Energy, 2013, 2, 1232-1241. 